\title{
Krankenkassen-Rahmenverträge für Ärzte
}

Profitieren Sie bereits von den Rabatten der FMH Insurance Services-Rahmenverträge, welche wir mit verschiedenen Krankenversicherern abgeschlossen haben? Falls nein, bestellen Sie kostenlos und unverbindlich ein persönliches Angebot. Von diesen Spezialkonditionen profitieren alle FMH Services-Mitglieder sowie im gleichen Haushalt wohnende Familienangehörige und Lebenspartner. Ein Beitritt ist bis Alter 65 möglich. Gerne beraten wir Sie auch bei der Wahl des für Sie am besten geeigneten Grundversicherungsmodells oder bei der Zusammenstellung der Zusatzversicherungen.

Wir verfügen über Rahmenverträge bei folgenden Krankenversicherern:

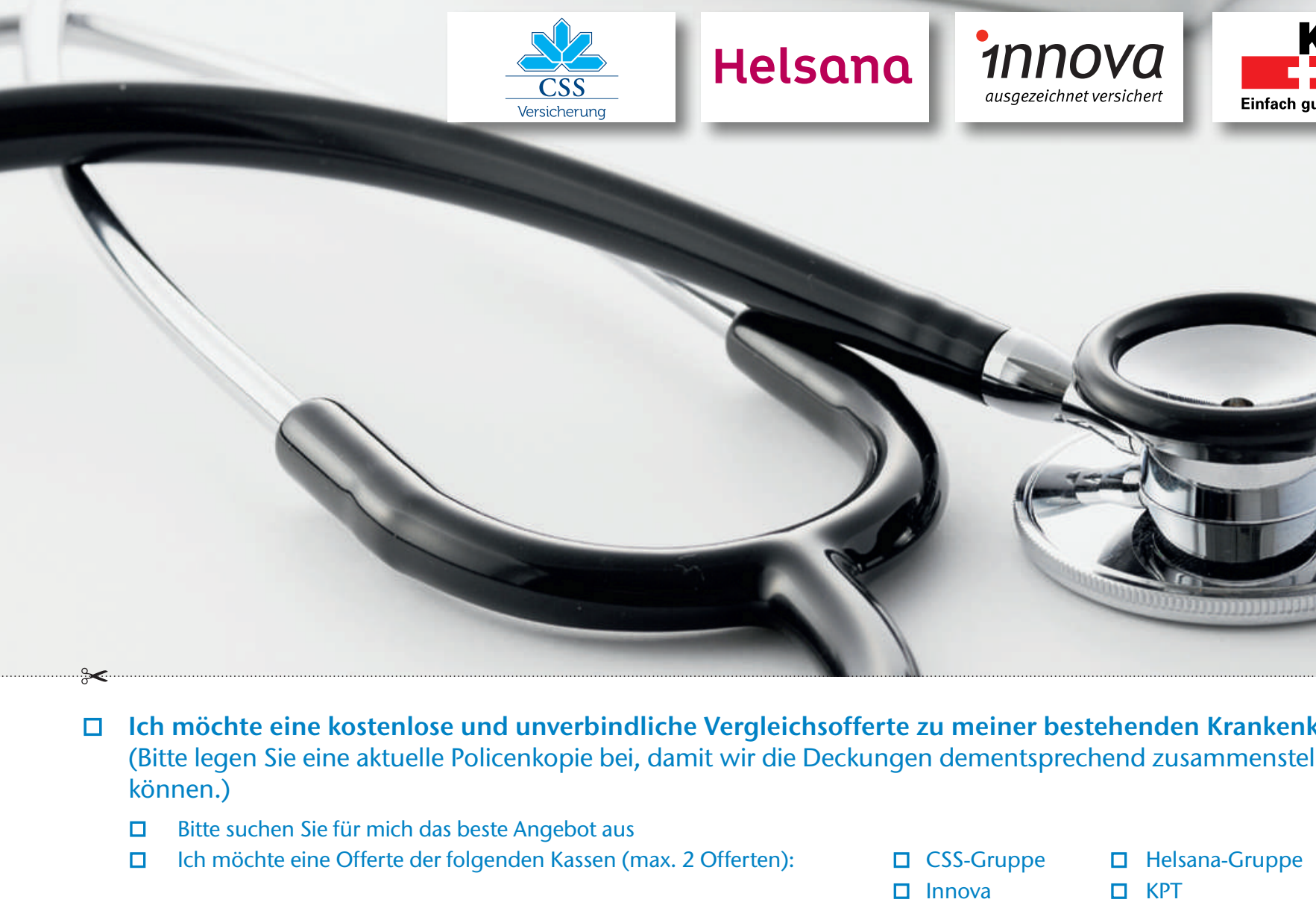

$\square \quad$ Ich wünsche eine persönliche Beratung. Bitte rufen Sie mich an.

$\square \quad$ Ich interessiere mich für weitere Produkte und Dienstleistungen:
$\square$ Berufshaftpflichtversicherung
$\square$ Rechtsschutzversicherung
$\square$ Taggeld
$\square$ Säule $3 a$
$\square$ Finanzplanung
$\square$ Pensionsplanung

Vorname / Name

Adresse

PLZ / Ort

Telefon Privat / Geschäft

Beste Zeit für einen Anruf

E-Mail-Adresse

$\begin{array}{ll}\square \text { CSS-Gruppe } & \square \text { Helsana-Gruppe } \\ \square \text { Innova } & \square \text { KPT }\end{array}$

Antworttalon: bitte einsenden oder per Fax an 0319595010

FMH INSURANCE

Roth Gygax \& Partner AG $₫$ Koordinationsstelle Moosstrasse 2 a 3073 Gümligen

Telefon 0319595000 — Fax 0319595010 mail@fmhinsurance.ch — www.fmhinsurance.ch 